\title{
On the Diurnal Variation of the Periods of Pc3, 4 Micropulsations*
}

\author{
J.C. Gupta and R.J. Stening** \\ Earth Physics Branch, Energy, Mines and Resources Ottawa, Ontario, Canada
}

(Received November 10, 1970)

\begin{abstract}
The period has been measured of each cycle of all Pc3, 4 micropulsation occurring on 10 days selected from a month's rapid run records collected during July-August, 1968 at four Canadian observatories. The periods are averaged over each hour and then the hourly values are averaged in two groups of five days according to the $C p$ value for the days. For Pc3 on the quieter days the diurnal variation of the periods shows a maximum peak near local noon while on disturbed days the variation changes to 'U-type' with the minimum period near noon. The Pc4 period is found to be lowest in the morning and highest in the evening at Ottawa and Meanook. But at higher latitudes (Baker Lake and Resolute Bay) the Pc4 period variation is simply 'U-type'. Analysis also shows the presence of a diurnal variation of the correlation between Pc periods and $K p$. The position of the plasmapause seems to determine Pc4 periods except at the higher latitudes while effects closer to the ionosphere may have a greater influence on the periods of Pc3 pulsations.
\end{abstract}

\section{Introduction}

The diurnal variation of $\mathrm{P}_{\mathrm{c}} 3$, 4 micropulsation periods has been studied by several workers. The most recent reviews of earlier work are given by Saito (1969) and Jacobs (1970) and it is evident that still more experimental work is needed. The previous investigations have been carried out with different volumes of data at different stations and at times of different magnetic activity but when they are all considered together the situation for Pc3 and Pc4 period range may be summarized (Saito, 1969) as follows: For periods up to about 20 seconds an inverted 'U-type' diurnal variation is found with maximum period near local noon (Kato and Saito, 1959; Campbell, 1959; Duncan, 1961; Ness et al., 1962; Saito and Matsushita, 1967) and for larger periods, 'U-type' variation occurs with minimum periods near local noon (Mainstone and McNicol, 1963; Christoffel and Linford, 1966; Stuart and Usher, 1966).

The present investigation is concerned with micropulsations in the Pc3 (10-45 seconds) and Pc4 (45-150 second) ranges. Four Canadian observatories (Table 1) provided a month's data during July and August, 1968. The studies reported here concern only the major horizontal component at each station (no records have been taken for Z-component). Ten days have been selected with a variety of magnetic activities (Table 2). On these days the period of each micropulsation cycle has been measured

*Contributions from the Earth Physics Branch No. 329.

**Presently at Department of Physics, University of the West Indies, Jamaica. 
Table 1.

\begin{tabular}{|c|c|c|c|c|c|c|c|}
\hline & \multirow{2}{*}{ Station } & \multicolumn{2}{|c|}{ Geographic (gg) } & \multicolumn{2}{|c|}{ Geomagnetic $(\mathrm{gm})^{*}$} & \multirow{2}{*}{$\begin{array}{c}\text { Components } \\
\text { Recorded }\end{array}$} & \multirow{2}{*}{$\begin{array}{c}\text { Components } \\
\text { analysed } \\
\text { to study } \\
\text { Pc3 \& Pc4 }\end{array}$} \\
\hline & & Latitude & Longitude & Latitude & Longitude & & \\
\hline 1 & Ottawa & $45.4^{\circ} \mathrm{N}$ & $75.6^{\circ} \mathrm{W}$ & $57.0^{\circ} \mathrm{N}$ & $8.5^{\circ} \mathrm{W}$ & $D, H$ & $H$ \\
\hline 2 & Meanook & $54.6^{\circ} \mathrm{N}$ & $113.3^{\circ} \mathrm{W}$ & $61.9^{\circ} \mathrm{N}$ & $59.3^{\circ} \mathrm{W}$ & $X, Y$ & $X$ \\
\hline 3 & Baker Lake & $64.3^{\circ} \mathrm{N}$ & $96.0^{\circ} \mathrm{W}$ & $73.9^{\circ} \mathrm{N}$ & $45.2^{\circ} \mathrm{W}$ & $X, Y$ & $X$ \\
\hline 4 & Resolute Bay & $74.7^{\circ} \mathrm{N}$ & $94.9^{\circ} \mathrm{W}$ & $83.1^{\circ} \mathrm{N}$ & $72.3^{\circ} \mathrm{W}$ & $X, Y$ & $Y$ \\
\hline
\end{tabular}

*Taking north geomagnetic pole coordinates $\left(78,3^{\circ} \mathrm{N}, 69.0^{\circ} \mathrm{W}\right)$

Table 2. Days used in period analysis

\begin{tabular}{|c|c|c|c|}
\hline Year 1968 & \multirow{2}{*}{$C p$} & \multirow{2}{*}{ Disturbed Days } & \multirow{2}{*}{$C p$} \\
\hline Quiet Days & & & \\
\hline July $\quad 24$ & 0.1 & August 8 & 0.8 \\
\hline August 4 & 0.2 & August 6 & 0.9 \\
\hline July $\quad 15$ & 0.3 & July $\quad 22$ & 1.0 \\
\hline August 10 & 0.4 & August 14 & 1.2 \\
\hline July 18 & 0.6 & August 16 & 1.5 \\
\hline
\end{tabular}

Table 3. Micropulsations in Pc3 Range

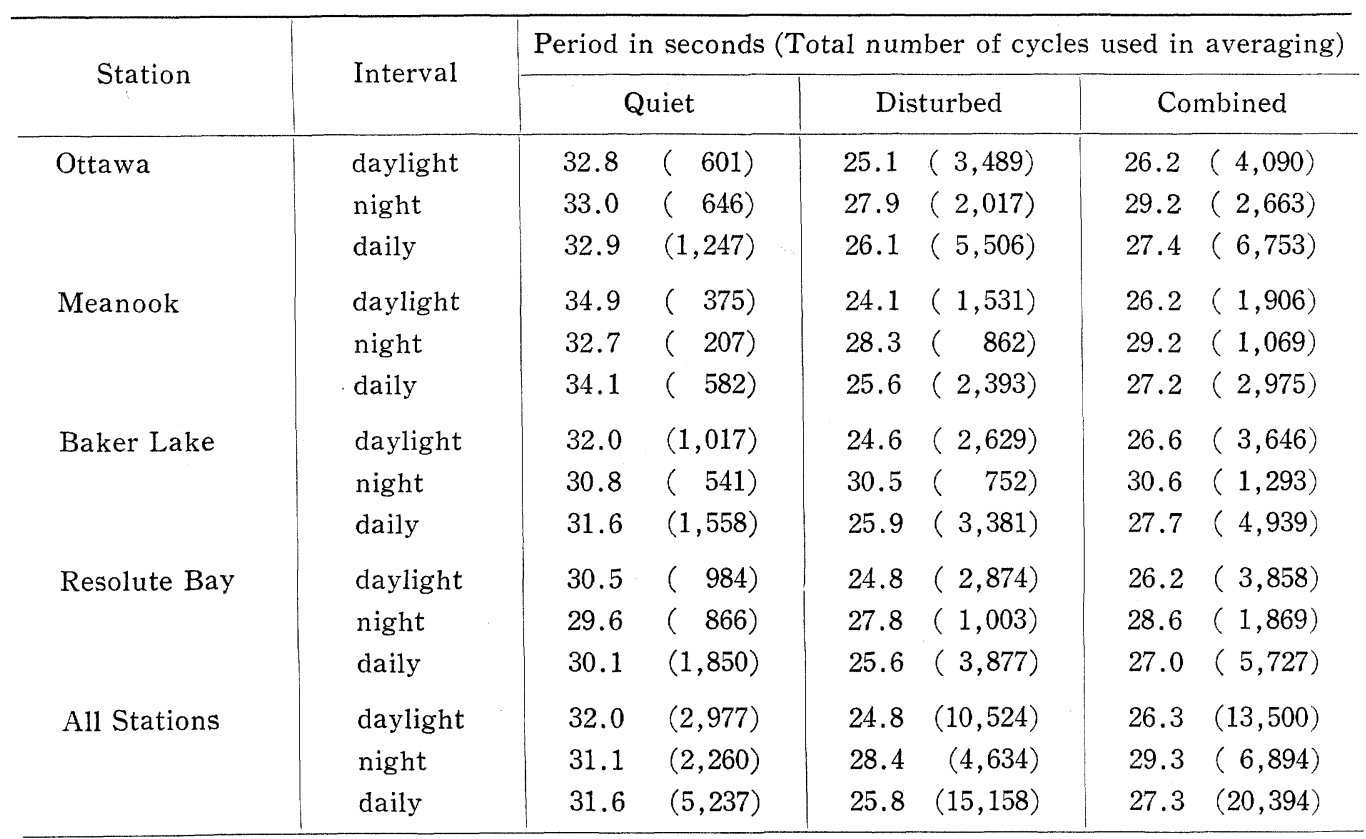


Table 4. Micropulsations in Pc4 Range

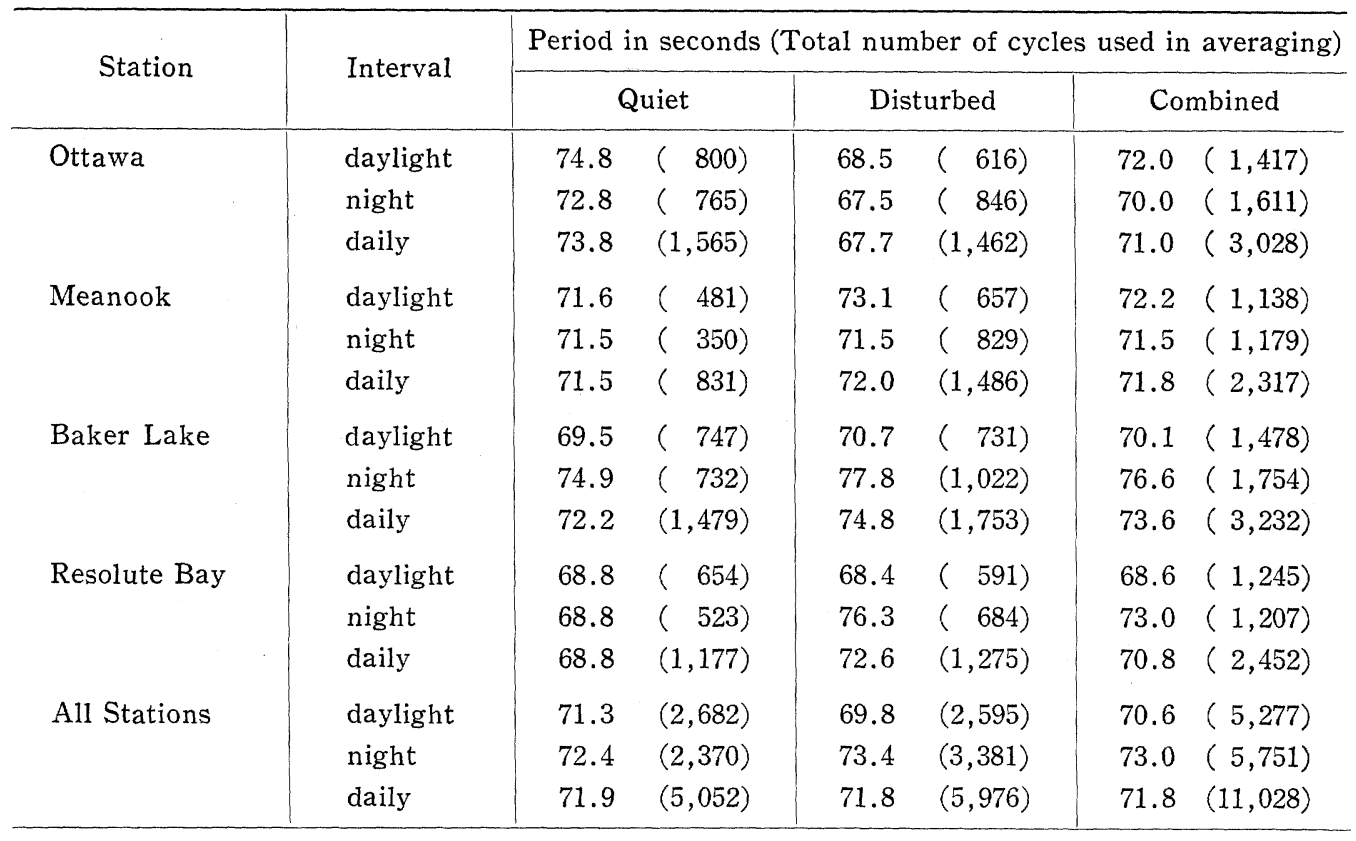

Daylight hours refer to 6-18h LMT
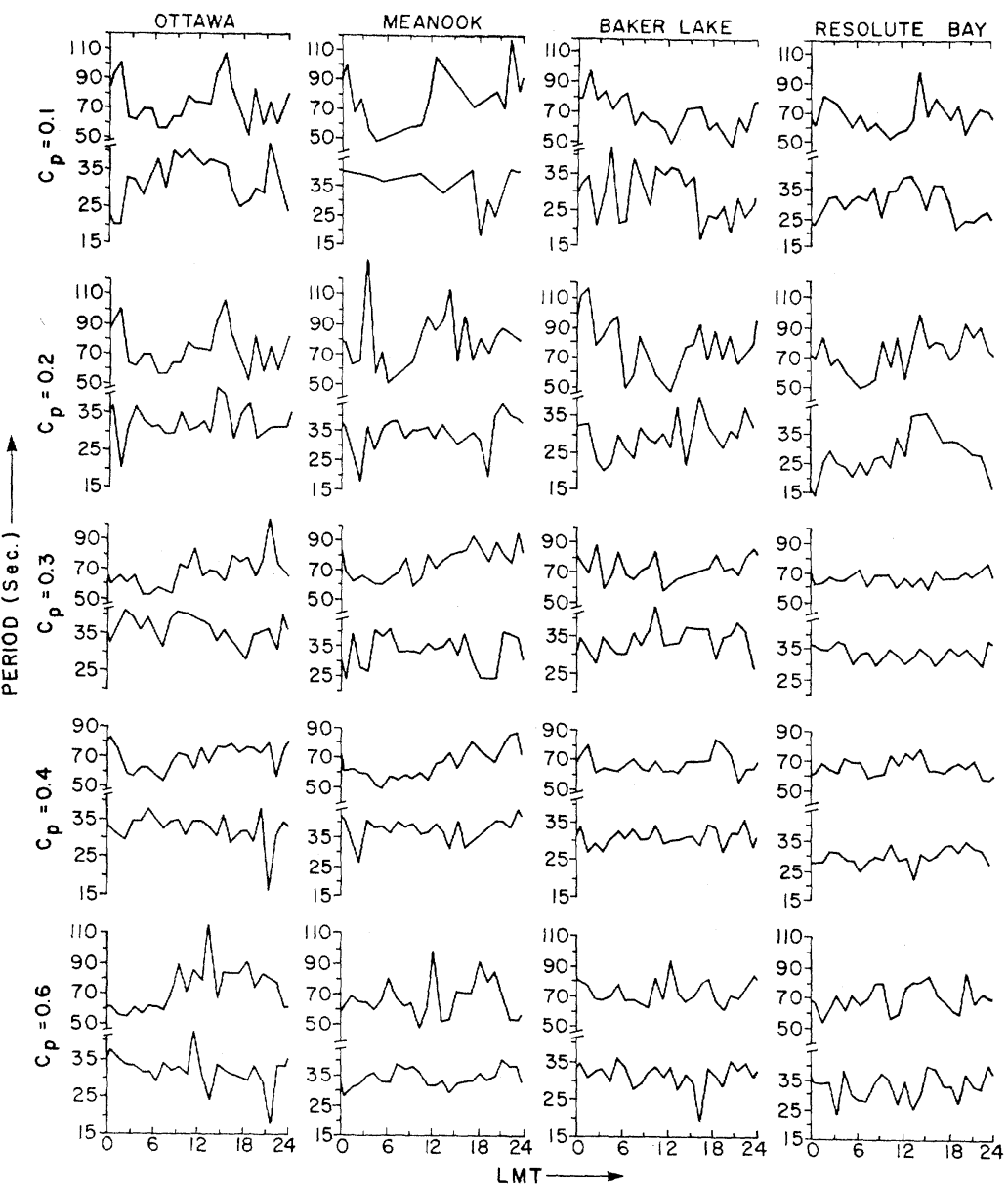

Fig. 1 Variation of the Pc3 (lower curve) and Pc4 (upper curve) periods during 24 hours of each of the five Quiet days on which $C p \leqslant 0.6$. 
to an accuracy of $0.5 \mathrm{~mm}$ (equivalent to 2 seconds). The numbers of cycles measured are noted in Tables 3 and 4 . The readings are first collected to find an average period of each hour of each day studied. The 24 hour diurnal variation of Pc3 and Pc4 periods for each of the 10 days studied are shown in Figs. 1 and 2. Since it is difficult to isolate systematic diurnal trends in these plots for individual days, the data are further averaged in two groups of 5 days each. One group included days with $C p \leqslant 0.6$ and these have been designated as magnetic 'Quiet' days, while the second group comprised days with $C p>0.6$ and these are designated as 'Disturbed' days. Finally the whole

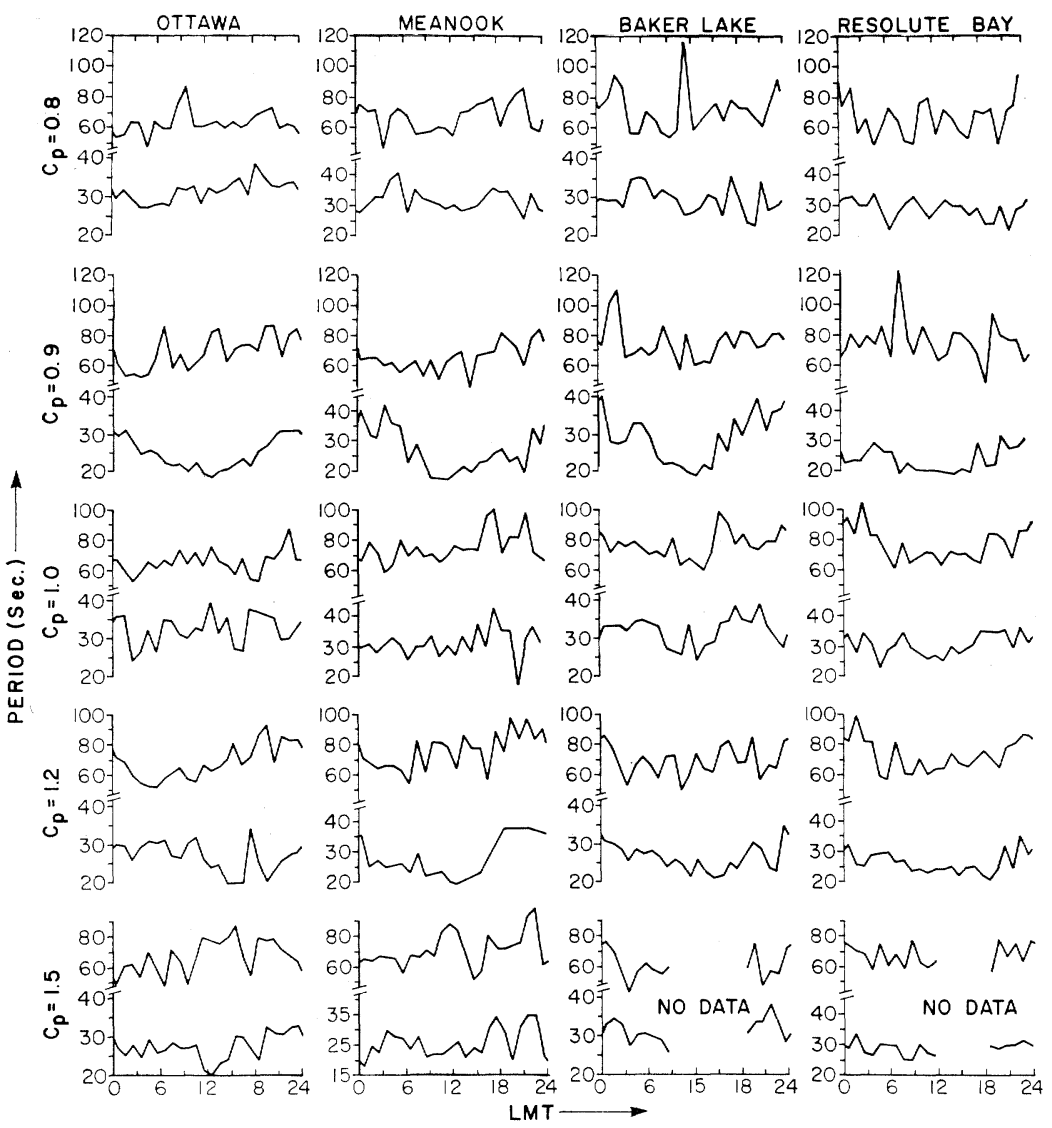

Fig. 2 Variation of the Pc3 (lower curve) and Pc4 (upper curve) periods during 24 hours of each of the five Disturbed days on which $C p>0.6$.

Table 5. Mean Standard Deviations (in seconds)

\begin{tabular}{l|c|c|c|c|c|c}
\hline \multirow{2}{*}{ Station } & \multicolumn{3}{|c|}{ Pc3 } & \multicolumn{3}{c}{ Pc4 } \\
\cline { 2 - 7 } & Quiet & Disturbed & Combined & Quiet & Disturbed & Combined \\
\hline Ottawa & 4 & 4 & 5 & 10 & 8 & 10 \\
Meanook & 4 & 5 & 6 & 12 & 9 & 11 \\
Baker Lake & 5 & 4 & 5 & 10 & 9 & 10 \\
Resolute Bay & 5 & 4 & 5 & 8 & 10 & 10 \\
\hline
\end{tabular}


ten days data (designated as Combined days) are averaged together to obtain an overall impression.

The diurnal variations on Quiet, Disturbed and Combined days are given in Fig. 3 for Pc3 and Fig. 4 for Pc4. The mean Standard deviations of the 24-hourly data points for these three groups are given in Table 5. It is considered sufficient to give only these because the standard deviations at the different 24 hourly points are found to be homogeneous for nearly all the cases, at 95\% confidence limit, by the Bartlett's test.

Further, by performing a $\chi^{2}$-test it is found that a Fourier Function $F(X)$ with four harmonic terms $(n=1$ to 4 ) is sufficient to represent these hourly data points of Pc3 and Pc4 (Braddick, 1954, pp. 40-42). This function is shown by the smoothed curves in

Table 6. T-test indicates the following coefficients to be significant at the $5 \%$ level

\begin{tabular}{l|c|c|c}
\hline \multicolumn{1}{c|}{ Station } & Days & Pc3 & Pc4 \\
\hline Ottawa & Q & $\mathrm{a}_{1}$ & $\mathrm{a}_{1}, \mathrm{~b}_{1}$ \\
& $\mathrm{D}$ & $\mathrm{b}_{1}$ & $\mathrm{a}_{1}, \mathrm{~b}_{2}, \mathrm{a}_{3}$ \\
$\mathrm{C}$ & & $\mathrm{a}_{1}, \mathrm{~b}_{1}$ \\
Meanook & $\mathrm{a}_{2}, \mathrm{a}_{3}, \mathrm{~b}_{3}, \mathrm{~b}_{4}$ & $\mathrm{a}_{1}, \mathrm{~b}_{1}$ \\
& $\mathrm{Q}$ & $\mathrm{b}_{1}, \mathrm{~b}_{2}$ & $\mathrm{a}_{1}, \mathrm{~b}_{1}, \mathrm{a}_{2}$ \\
& $\mathrm{D}$ & $\mathrm{a}_{1}, \mathrm{~b}_{4}$ & $\mathrm{a}_{1}, \mathrm{~b}_{1}, \mathrm{a}_{2}$ \\
Baker Lake & $\mathrm{a}_{2}$ & $\mathrm{~b}_{1}, \mathrm{~b}_{2}, \mathrm{a}_{3}$ \\
& $\mathrm{C}$ & $\mathrm{b}_{1}, \mathrm{a}_{2}$ & $\mathrm{~b}_{1}, \mathrm{a}_{3}$ \\
& $\mathrm{D}$ & $\mathrm{b}_{1}$ & $\mathrm{~b}_{1}, \mathrm{~b}_{2}, \mathrm{a}_{3}, \mathrm{~b}_{3}$ \\
& $\mathrm{C}$ & $\mathrm{b}_{1}$ & $\mathrm{~b}_{1}$ \\
Resolute Bay & $\mathrm{Q}$ & $\mathrm{a}_{1}$ & $\mathrm{a}_{1}, \mathrm{a}_{4}$ \\
& $\mathrm{D}$ & $\mathrm{b}_{1}$ \\
\hline
\end{tabular}

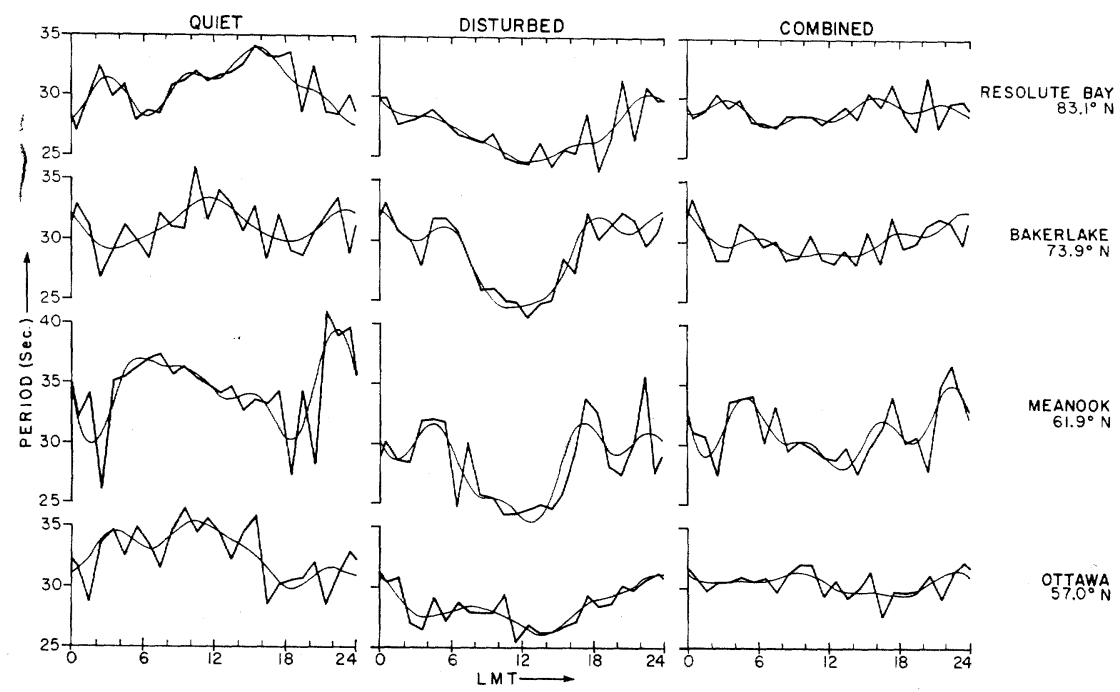

Fig. 3 Diurnal variation of average Pc3 periods for five 'Quiet' days $(C p \leqslant 0.6)$, five 'Disturbed' days $(C p>0.6)$ and for the ten days combined. 


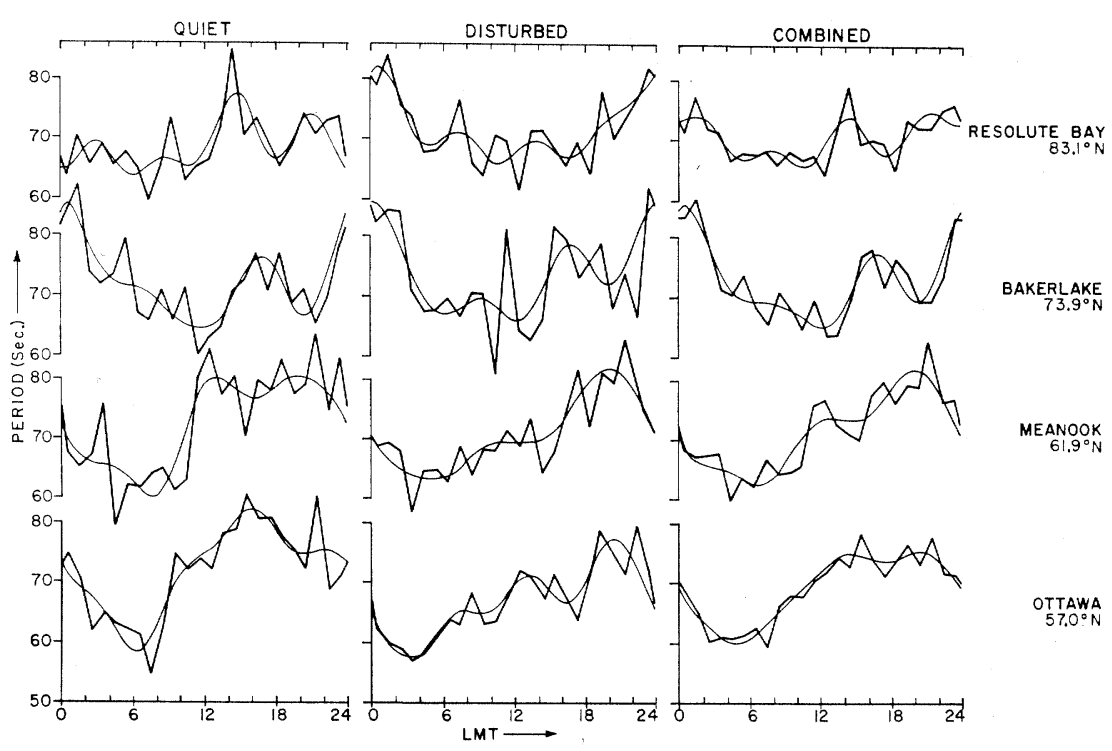

Fig. 4 Diurnal variation of average Pc4 periods for five 'Quiet' days $(C p \leqslant 0.6)$, five 'Disturbed' days $(C p>0.6)$ and for the ten days combined.

Figs. 3 and 4 .

Finally, the T-test, which is the usual test in least squares problems, has been used to test the significance of the Fourier Coefficients. Those which are found significant at $5 \%$ level are given in Table 6 . Clearly the diurnal or in some cases the semi-diurnal (cf. Meanook and Baker Lake Pc3, Quiet) trends seen in Figs. 3 and 4 may be considered real. Also, in the case of Pc3 for Quiet and Disturbed days in general, opposite coefficients (i.e., $a$ or $b$ ) are found to be significant at the four stations.

\section{Diurnal Trends of the Periods}

\section{(1) In the Pc3 Range}

It is first noticed from Fig. 3 that on Quiet days the variations are roughly similar at the four stations; having a maximum period near noon with also an extra peak appearing at night. On the other hand the disturbed days show a clear 'U-type' variation at all stations with a minimum period around noon.

In Table 3 the average periods for daytime, night-time and the whole day are listed. The difference between the average day and night periods is insignificant on Quiet days at all stations. On Disturbed days the 'U-type' variation gives rise to a lower period during the day. No clear latitude-dependence of the periods is found. On Quiet days the average period ranges from a maximum at Meanook to a minimum 4.4 seconds lower at Resolute Bay in the daytime while at night the difference between the maximum at Ottawa and the minimum at Resolute Bay is only 3.4 seconds. On the basis of the data presented here these differences cannot be considered as significant. On Disturbed days the latitude dependence is even less significant. This process of averag- 
ing periods has been criticised (Gupta and Stening, 1971) since the periods observed in different hours and on different days vary so much. Here it is seen that, even when periods are averaged, their dependence on latitude is doubtful. This agrees also with the work of Ellis (1960), Orange and Bostick (1965), Herron and Heirtzler (1966) and Stening and Gupta (1971).

On Disturbed days the times and values of the maxima and minima are roughly the same at all stations. There is clearly a reduction in period on Disturbed days compared to Quiet days and, except at Meanook, the reduction is much greater in the minimum period than in the maximum period. i.e. the disturbance effect is greatest in the middle of the day.

(2) In the Pc4 Range

It is immediately seen from Fig. 4 that Ottawa and Meanook show one kind of variation with a minimum period in the morning and a maximum in the afternoon in both Quiet and Disturbed days. On the other hand the northernmost stations, Baker Lake and Resolute Bay, have a 'U-type' variation with minimum period near midday (Resolute Bay shows no clear variation on Quiet days).

Details of the Pc4 period variations are given in Table 4. A small difference between average day and night periods only shows when there is a 'U-type' diurnal variation -on Disturbed days at Resolute Bay and at all times at Baker Lake. As mentioned above, in view of our method, such differences in the average period may not be considered very significant. The latitude dependence of period varies. During the day the maximum average period occurs at Ottawa on Quiet days and at Meanook on Disturbed days (Table 4). At night the maximum always falls at Baker Lake. The maximum and minimum periods in the diurnal curves are both most extreme at Ottawa on Quiet days where the variation is from 58 to 86 seconds. The most notable change from Quiet to Disturbed days is the lowering of the maximum of the Ottawa variation from 86 to 76 seconds.

\section{Correlation of $\mathrm{Pc} 3,4$ periods with $\mathrm{Kp}$}

Hitherto it has been generally thought that Pc periods show an inverse correlation with $K p$ at all times (e.g., Nagata and Fukunishi, 1968). The possibility of a variation of the correlation with time of day does not appear to have been previously considered explicitly. Accordingly the variation with local time of the correlation coefficient of the average Pc period over a three-hour interval with the $K p$ of that interval is presented in Fig. 5. These curves are probably only an approximate representation of some real variations, because very few data points were available to compute the correlation coefficients and the upper and lower confidence limits differ by about 0.8 for the majority of the points. (To avoid clustering the confidence limits on the individual points are not shown.)

It is first noticed that Pc3 periods have a higher correlation with $K p$ during the day than at night. This is in accord with our previous observation that disturbance changed 


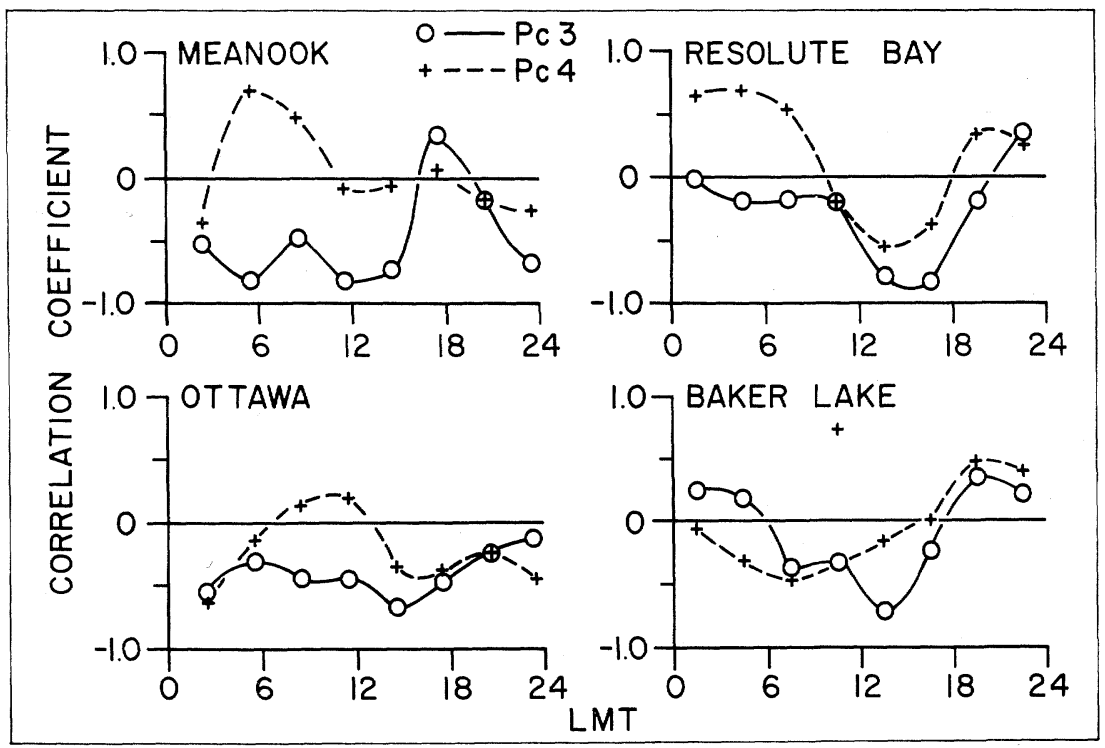

Fig. 5 Diurnal variation of the correlation of Pc periods with $K p$. Full lines-Pc3, dashed lines-Pc4.

the Pc3 periods most during daytime. At Baker Lake and Resolute Bay the correlation becomes very low or even positive at night. Pc4 periods generally have less inverse correlation with $K p$ than $\mathrm{Pc} 3$ and sometimes show significant positive correlation. Whereas for Ottawa and Meanook the Pc3 and Pc4 curves show little resemblance, there is some similarity between the two at Baker Lake and Resolute Bay (if the $1030 \mathrm{~h} \mathrm{Pc4}$ point at Baker Lake is neglected).

It has been found that the position of the plasmapause changes with the value of $K p$ with a delay of some 2 to 6 hours between the $K p$ value and the plasmapause finding its position (Chappell et al., 1970). A similar delay has been found between neutral air density increases at satellite heights and increases in $K p$ (De Vries et al., 1967). A search was therefore made for such a delay for maximum anticorrelation between Pc periods and $K p$. With just 10 days data, only a glimpse of any effect is expected. Even after introduction of delays, at many local time periods the anticorrelation still remained low, particularly for Pc4. But there were other cases where a noticeably larger anticorrelation coefficient was found when a delay was included. A 9 hour delay was required for Ottawa Pc4 around local noon (13-16h LT) when the correlation coefficient moved from -0.36 with no delay to -0.64 with 9 hours delay). A similar but less significant delay was seen at Meanook. On the other hand Pc3 periods were best anticorrelated with $K p$ at these stations near noon with zero delay included. At Baker Lake and Resolute Bay, for Pc3, a delay of 6 to 9 hours is found in the morning but zero delay in the early afternoon. Pc4 periods at these northern stations do not give significant correlation even after the inclusion of delays and in many cases the coefficients remain positive. With the limited amount of data available for this study it is not possible to discuss 
statistically the effect of delays in correlation coefficients. However, these preliminary results are sufficiently encouraging to suggest that this aspect merits further study.

\section{Discussion}

\section{(1) Pc3}

Since all the average Pc3 periods discussed in this paper are greater than 21 seconds, the summary presented in the introduction would lead one to expect 'U-type' diurnal variation. Our study has shown this effect only on disturbed days and other recent work has led to further complications. Duncan (1961) said that his sonagrams gave a falling tone starting at dawn, that is, a steady increase in period during the day. Hirasawa and Nagata (1966) found an average sonagram with a similar diurnal period variation for Pc3, as did Voelker (1964). At latitudes 55 $-70^{\circ}$ Hirasawa (1969) found a roughly 'U-type' variation. Channon and $\operatorname{Orr}(1970)$ at an equatorial station found for $K p=$ $0-2$, a decrease in period throughout the day. At $K p=2+$ to $4+$ they found a maximum period near $0200 \mathrm{~h}$ and a minimum at about 1500 LT. Nagata and Fukunishi (1968) find a 'U-type' variation at Kakioka with the time of minimum period moving from noon towards the earlier morning at higher $K p$ values. Our results show rather a movement from the evening towards noon.

The mid-day maximum period found by us on quiet days does not appear to have been noted previously in this period range ( $>20$ seconds). It may be that it occurs only at stations of high latitude $\left(>60^{\circ}\right)$. Saito and Matsushita (1967) explained the 'U-type' variation of $\mathrm{Pc} 3$ period found by Christoffel and Linford (1966) over against their inverted 'U-type' findings by suggesting that 'inverted U-type' occurs at maximum solar cycle and 'U-type' at minimum solar cycle. Our results are from the maximum period (sun-

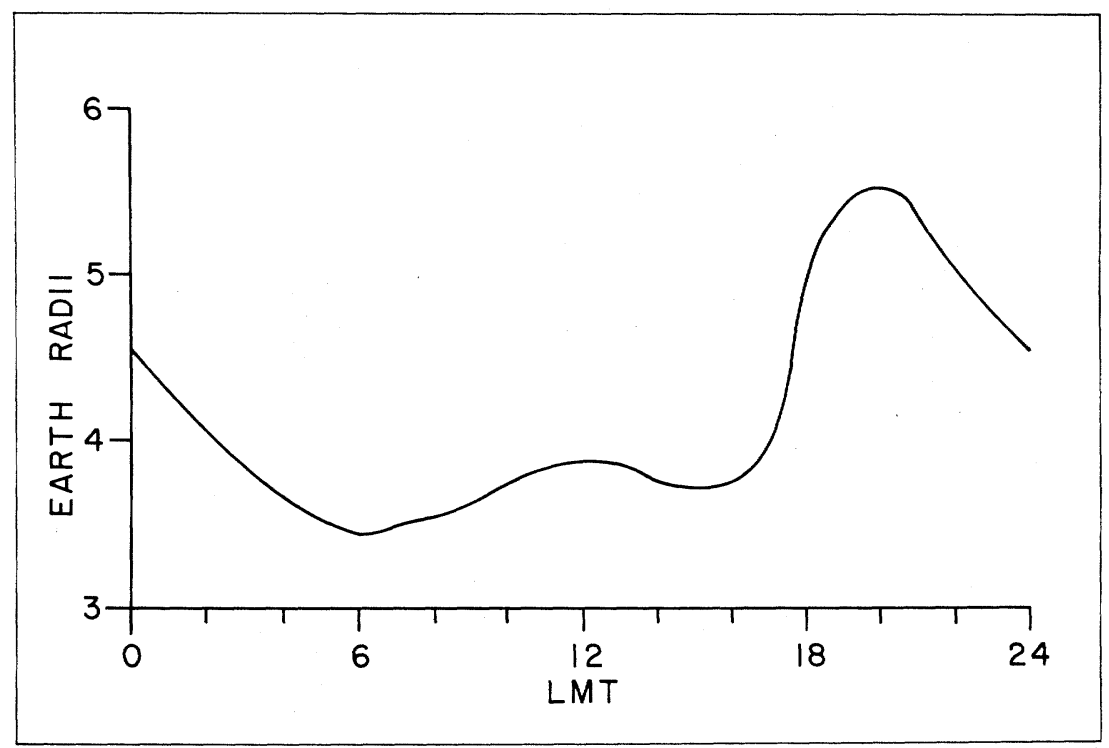

Fig. 6 Diurnal variation of equatorial distance of plasmapause (from Carpenter, 1966). 
spot numbers are 106.0 for July and 106.1 for August, 1968). The change-over from a mid-day maximum ('inverted U-type') to 'U-type' in our results depends rather on the daily magnetic activity. (This change seems to occur between $C p=0.4$ and $C p=$ 0.6.)

The mid-day maximum period cannot be simply explained. At the time of the evening minimum especially there is a low correlation of period with $K p$. We therefore might expect the cause to be lower in the atmosphere and may be associated with ion density reductions above the $F$-region which occur near 20-21 hours (Gordon, 1967). (This follows from the relation $T=4 \pi^{1 / 2} \int H^{-1} N^{1 / 2}$ ds where $H, N$ and $s$ are respectively the magnetic field intensity, ion density on the path and the path length of the Alfvén wave.) The morning minimum seems rather too early to associate with the dawn $F$ region density trough. This will require further investigation.

Nagata and Fukunishi (1968) have suggested that Pc3 periods reflect movements in the position of the plasmapause but our results show little support for this idea. The diurnal variation of the plasmapause position (Carpenter, 1966) predicts a maximum period near 18-21 h LT (Fig. 6) for Alfvén waves in a plasmapause cavity but we find a minimum at this time on our quieter days. This is probably due to the ionospheric effects mentioned above. Furthermore the expected delay for the plasmapause to find its new position during daytime after a change in $K p$ (Grebowsky, 1970) is not found in the anticorrelation of $\mathrm{Pc} 3$ periods with $K p$ at the lower latitude stations. Baker Lake and Resolute Bay lie beyond the plasmapause and so other factors must certainly be considered to control Pc3 period variation at these stations.

(2) $\quad P c 4$

In this period band recent results also differ from the 'U-type' variation described by Saito (1969). Hirasawa and Nagata (1966) and Nagata and Fukunishi (1968) find a maximum period in the evening and a minimum in the morning similar to our results at the two sub-auroral stations (Ottawa and Meanook). This variation is very similar to the variation of the equatorial distance to the plasmapause (Fig. 6). Further evidence supporting the origin of these pulsations as transverse $H M$ waves on the plasmapause is found in our results. The marked difference between the diurnal variations at stations within the plasmapause (Ottawa and Meanook) and those outside (Baker Lake and Resolute Bay) argues for a different resonating system for Pc4 in the two regions. The plasmapause position is governed by the interaction of corotating plasma with convective flow from the geomagnetic tail (Nishida, 1966) and so some delay is expected between $K p$ changes and movement of the plasmapause. We find this to be particularly true in the noon sector. Satellite results (e.g., Chappell et al., 1970) also indicated delays of 2 to 6 hours at night, while the delay during day-time was not clear.

We may thus use our Pc4 period results to make predictions of plasmapause movements. The Ottawa Pc4 results indicate an earlier time for the minimum period on Disturbed days and so the time of closest approach of the plasmapause to the earth should be earlier during disturbed times. This seems reasonable as the increased flow from 
the tail on the night side should compress the corotating plasma more towards the midnight meridian. On the other hand the change in Pc4 period from quiet to disturbed times is greater in the evening than in the morning at Ottawa so the increased compression of the plasmapause during disturbance seems to be greater in the region of its maximum distance in the evening than in the region of its minimum distance.

Pc4 period variations at the two northern stations (Baker Lake and Resolute Bay) do not reflect plasmapause movements, as might perhaps be expected. Rather they seem similar to the Pc3 period variations and may be harmonically related to Pc3 pulsations. At these stations the increase in average period on disturbed days is greater at night (seen also in Fig. 5). Gupta and Stening (1971) found indications (in analysis of daytime records) that this increase in average period was due to the appearance of additional longer period pulsations at more disturbed times. However, at Ottawa all the positive correlation with $K p$ may be removed by introducing an appropriate delay time.

The ratio of Pc4 period to Pc3 period has also been calculated. When data from all stations are pooled, this ratio is 2.6 when all days are included, with a change from 2.3 on quiet days to 2.8 on disturbed days. Nagata and Fukunishi (1968) found a ratio of about 3 for periods of transverse waves generated on the surface of the plasmapause (Pc4) to longitudinal waves within the plasmapause (Pc3).

\section{Acknowledgments}

The records used in this work were obtained by Mr. G. Jansen van Beek and the authors gratefully acknowledge his help. The tedious measurement of the micropulsation periods and analysis was performed by Messrs. L. Newitt and W. Marshall. Drs. E.R. Niblett and P.H. Serson provided helpful encouragement and discussion. For assistance in the statistical analysis of the data the authors gratefully acknowledge the help accorded by Mr. G.V. Haines. One of the authors (RJS) acknowledges receipt of a Postdoctorate Fellowship from the National Research Council of Canada.

\section{References}

Braddick, H.J.J., The Physics of experimental method, Chapman \& Hall Ltd., London, 1954.

Campbell, W.H., A study of micropulsations in the earth's magnetic field. Inst. Geophys. Univ. Calif. Los Angeles, Sci. Rep. 1, 333(57), 1-138, 1959.

Carpenter, D.L., Whistler studies of the plasmapause in the magnetosphere-Temporal variations in the position of the knee and some evidence on plasma motions near the knee. J. Geophys. Res., 71, 693-709, 1966.

Channon, M.J., and D. Orr, A study of equatorial geomagnetic micropulsations. Planet Space Sci., 18, 229237, 1970.

Chappell, C.R., K.K. Harris and G.W. Sharp, A study of the influence of geomagnetic activity on the location of the plasmapause as measured by OG05, J. Geophys. Res., 75, 50-56, 1970.

Christoffel, D.A. and J.G. Linford, Diurnal properties of the horizontal geomagnetic micropulsation field in New Zealand. J. Geophys. Res., 71, 891-897, 1966.

De Vries, L.L., E.W. Friday and L.L.C. Jones, Analysis of density data reduced from low-altitude, high resolution satellite tracking data. Space Res., 7, 1173-1182, 1967. 
Duncan, R.A., Some studies of geomagnetic micropulsations. J. Geophys. Res., 66, 2087-2094, 1961.

Ellis, G.R.A., Geomagnetic micropulsations. Austral. J. Phys., 13, 625-632, 1960.

Gordon, W.E., F-region and magnetosphere, back-scatter results. Rev. Geophys., 5, 191-205, 1967.

Grebowsky, J.M., Model study of plasmapause motion. J. Geophys. Res., 75, 4329-4333, 1970.

Gupta, J.C., R.J. Stening and G. Jansen van Beek, A study of micropulsations in the Pc3, 4 period ranges at four Canadian observatories. J. Geophys. Res., 76, 933-946, 1971.

Gupta, J.C. and R.J. Stening, Period structure of Pc3, 4 micropulsations. Planet. Space Sci., 19, 715-722, 1971.

Herron, T.J. and R.J. Heirtzler, Latitude-period dependence of geomagnetic micropulsations. Nature, 210, 361-363, 1966.

Hirasawa, T. and T. Nagata, Spectral analysis of geomagnetic micropulsations from 0.5 to $100 \mathrm{sec}$ in period for the quiet sun conditions. Pure Appl. Geophys., 65, 102-124, 1966.

Hirasawa, T., Worldwide characteristics of geomagnetic Pc pulsations with the period from 10 to 150 seconds during active-sun years. Repts Ionospheric and Space Res. Japan, 23, 281-293, 1969.

Jacobs, J.A., Geomagnetic Micropulsations. Physics and Chemistry in Space vol. 1, Springer-Verlag, 1970.

Kato, Y. and T. Saito, Preliminary studies on the daily behaviour of rapid pulsations. J. Geomagn. Geoelectr., 10, 4, 221-225, 1959.

Mainstone, J.S., R.W.E. McNicol and J.R. Wilkie, Micropulsation studies at Brisbane, Queensland; 2. Pulsations of Pc and Pt type. Proc. Int. Conf. Ionosphere Lond, (1902) Inst. Phys. and Phys. Soc., London, pp. 169-176, 1963.

Nagata, T. and H. Fukunishi, Dependence of geomagnetic activity of magnetic pulsation frequency of Pc3 and Pc4 range. Geophys. J. Roy. Astron. Soc., 15, 69-78, 1968.

Ness, N.F., T.L. Skillman, C.S. Scearce and J.P. Heppner, Magnetic field fluctuations on the earth and in space. Journ. Phys. Soc. Japan, 17, Suppl. AII, Part II, 27-33, 1962.

Nishida, A., Formation of plasmapause or magnetospheric plasma knee, by the combined action of magnetospheric convection and plasma escape from the tail. J. Geophys. Res., 71, 5669-5679, 1966.

Orange, A.S. and F.X. Bostick, Magnetotelluric micropulsations at widely separated stations. J. Geophys. Res., 70, 1407-1413, 1965.

Saito, T., Geomagnetic pulsations. Space Sci. Rev., 10, 319-412, 1969.

Saito, T., and S. Matsushita, Geomagnetic pulsations associated with sudden commencements and sudden impulses. Planet. Space Sci., 15, 573-587, 1967.

Stening, R.J. and J.C. Gupta, Amplitudes and periods of geomagnetic micropulsations in the Pc3, 4 range at Canadian observatories, Geophys. J. Roy. Astron. Soc., 23, 379-386, 1971.

Stuart, W.F. and M.J. Usher, An investigation of micropulsations at middle latitudes. Geophys. J. Roy. Astro. Soc., 12, 71-86, 1966.

Voelker, H., On the latitude-dependence of Pc-type micropulsations, Results of observations on a northsouth profile through Europe, Symposium on ultra low frequency electromagnetic fields, Boulder, N.B.S. Rep. 8815, 1964. 